\title{
Wind Energy Resource Assessment and Feasibility Study of Wind Farm in Mustang
}

\author{
Mukesh Ghimire, Ram C. Poudel, Nawraj Bhattarai, Mahesh Chandra Luintel \\ Pulchowk Campus, Institute of Engineering, Tribhuvan University, Nepal \\ Corresponding email: mukeshghi@yahoo.com
}

\begin{abstract}
This study presents the wind energy resource assessment and financial analysis of a 15 MW proposed wind farm in Mustang for utility scale power generation. Hourly meteorological data at Kagbeni and Thini measured at $10 \mathrm{~m}$ and $20 \mathrm{~m}$ height from 2001 to 2005 have been analyzed and the annual average wind speed and power density $75 \mathrm{~m}$ above ground level at Kagbeni are $8.05 \mathrm{~m} / \mathrm{s}$ and $851 \mathrm{~W} / \mathrm{m} 2$ whereas the same for Thini is $6.99 \mathrm{~m} / \mathrm{s}$ and $337 \mathrm{~W} / \mathrm{m} 2$, respectively. WAsP analysis shows that the wind speed and wind power density in the study area $(20 \times 20 \mathrm{~km} 2)$ varies from 2.72 $\mathrm{m} / \mathrm{s}$ to $44.51 \mathrm{~m} / \mathrm{s}$ and $0.23 \mathrm{~kW} / \mathrm{m} 2$ to $173.27 \mathrm{~kW} / \mathrm{m} 2$. Optimized layout of a $15 \mathrm{MW}$ wind farm that is comprised of twenty-five S52 $-600 \mathrm{~kW}$ turbines, developed by openWind software, yields annual gross energy $63.58 \mathrm{GWh}$, and net energy $41.66 \mathrm{GWh}$ with a capacity factor of $31.68 \%$. The economic analysis of the farm suggests that the unit energy cost is in the range of NRs 4.57 to NRs 6.10 under different energy availability scenarios when meeting the project MARR of $16.1 \%$. Based on the results, it is apparent that the wind resources at Mustang are suitable for harnessing wind energy especially for the purpose of utility scale electricity generation. Site accessibility is a major challenging factor to establish a wind farm currently.
\end{abstract}

Keywords: WAsP, openWind, Resource Assessment, Wind Farm, Feasibility Study.

\section{Introduction}

Wind is still an unharnessed energy resource in Nepal. Studies made for the World Bank in 1977 indicate that the Khumbu area is a high potential area. The study by DANGRID, a Danish consulting firm, in 1992 reported a potential to generate $200 \mathrm{MW}$ of electrical power with an annual energy production of $500 \mathrm{GWh}$ from the wind resources along the $12 \mathrm{~km}$ valley between Kagbeni and Chusang in the Mustang District [1]. The potential however was not estimated. A preliminary survey of the Department of Hydrology and Meteorology (DHM) indicates that wind energy can be harnessed for generating electricity in the hills and pumping water in Terai for irrigation during the dry season. The Water and Energy Commission Secretariat (WECS) along with DHM, Alternative Energy Promotion Center (AEPC) and Nepal Academy of Science and Technology (NAST) carried out a study on the potential of wind resources in Nepal in 19992002. The results show that there is a high potential of wind energy in many hills, with the exception some locations.

Nepal, without proper wind energy resource assessment and detailed technical analysis for wind power development, has already faced failure. An initiative undertaken by the Nepal Electricity 
Authority (NEA) in 1989 to produce power by installing two wind generators of $10 \mathrm{~kW}$ capacities experienced negative results within three months of project commencement [1]. This has acted as a major barrier for wind power development in Nepal and it has been regarded as a waste of resources. Therefore, very few developers are interested in wind energy investments.

SWERA, the first project of its kind in Nepal, was conducted by AEPC in a domestic partnership with the Center for Energy Studies (CES), Institute of Engineering, Tribhuvan University. SWERA has made an attempt to assess the wind energy resources of the whole country. It especially focuses on the buffered area within the grid connection and it also has made a separate study for the Annapurna Conservation Area (ACAP). With limited wind data, this analysis shows that $3000 \mathrm{MW}$ of electricity could be generated from wind energy. This includes the conclusion that $10 \%$ of Nepal has a potential of more than $300 \mathrm{~W} / \mathrm{m}^{2}[2,3]$.

Presently, there is no other intensive study related to wind energy resource assessment in Nepal. The SWERA study is limited to meso-scale energy estimation from installed wind anemometers at different sites. Currently, the Government of Nepal $(\mathrm{GoN})$ has planned and budgeted for 20 MW of electricity from wind energy near the Kathmandu valley and AEPC is collecting wind data from various stations across the country [5]. A study focusing on a specific site, for the potential establishment of a wind farm and its impact on grid integration has yet to be done. Similarly, in Nepal there is no study concerning optimum energy production from a wind farm along with technical and economical evaluation. In such a scenario a detailed analysis for constructing a wind farm in a recommended site is very necessary. This study aims to estimate annual energy production and also establish a basic procedure for individual-site wind energy resource assessment, including detailed technical and financial analysis.

\section{Methodology of the Study}

This study has a quantitative approach for wind data analysis and energy resource assessment and a qualitative evaluation of the results obtained from various software tools. The following methods and materials have been adopted during the study:

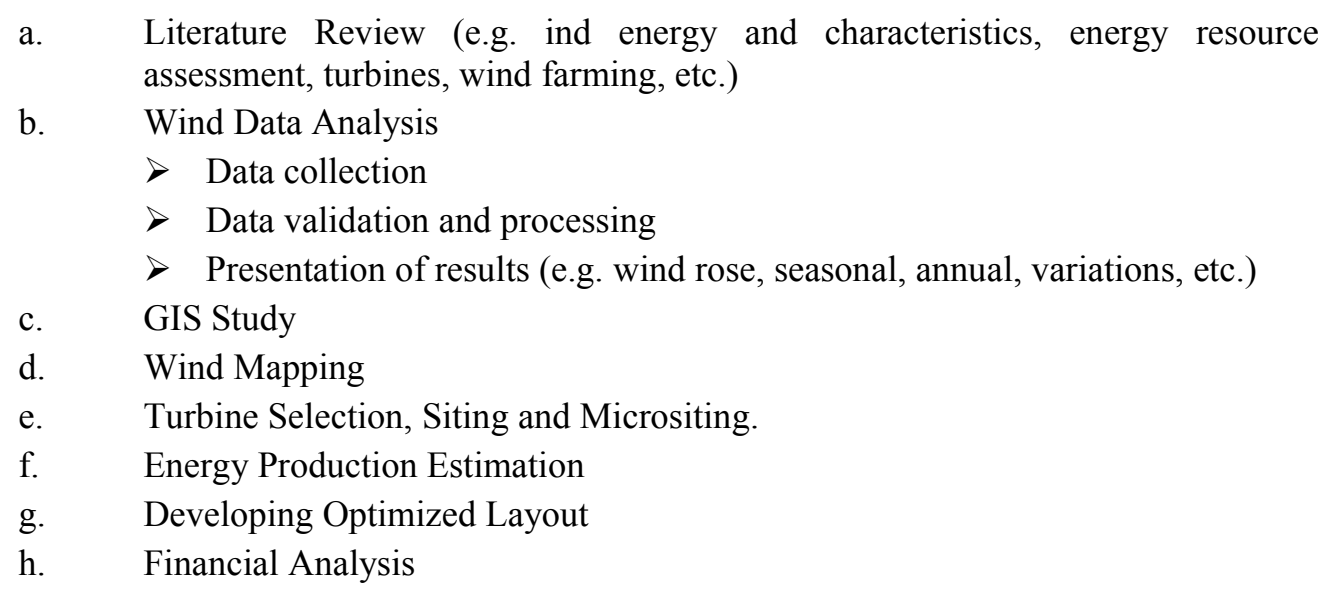

\section{Site Location}

For study relevance, a site was selected in the Mustang District. The focus area is a $20 \times 20 \mathrm{~km}^{2}$ area near the periphery of the following two wind mast stations: Thini and Kagbeni (Figure 1). 
Both are located near the Kaligandaki riverbank. The Thini wind mast is near Jomsom, the district headquarters, whereas Kagbeni is $8.2 \mathrm{~km}$ further north, on the way to upper mustang.
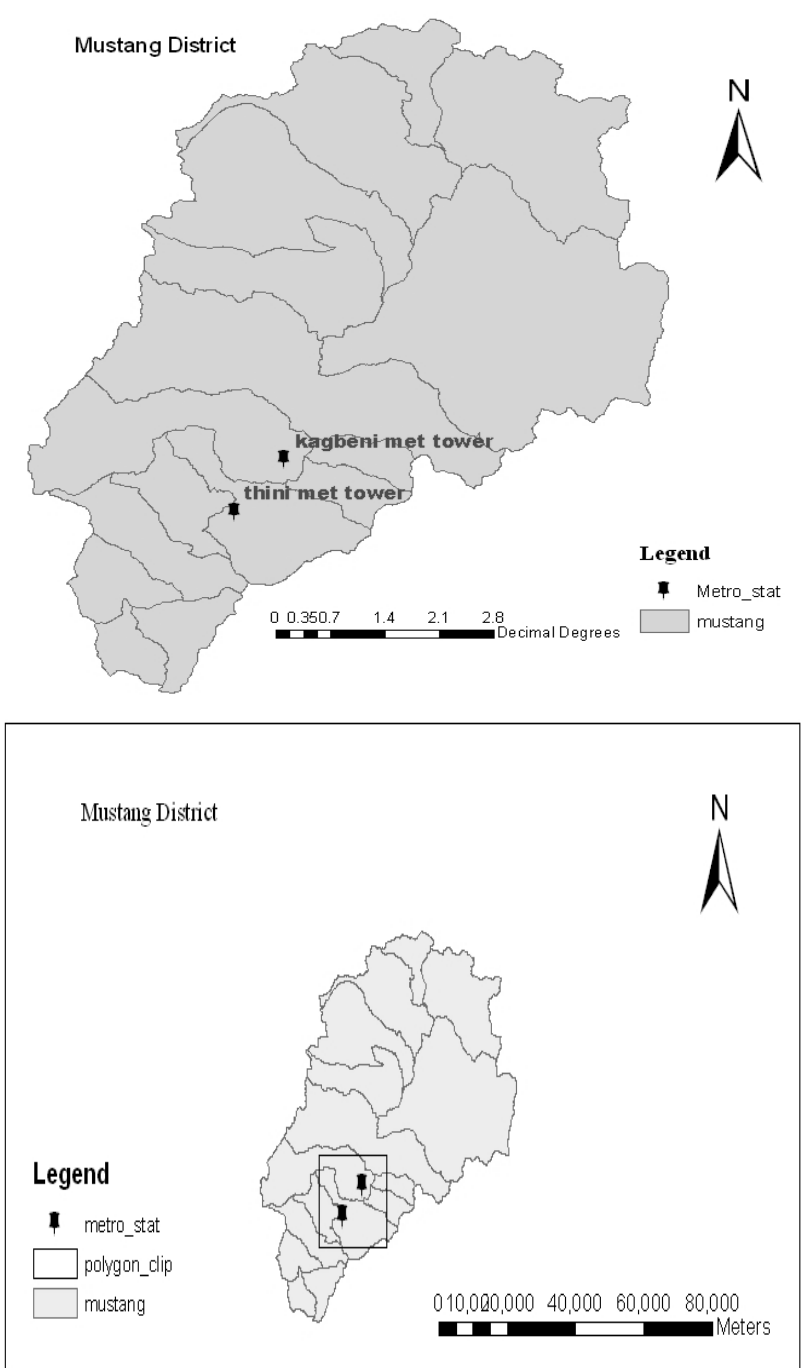

Figure 1: Study Area Location Map

\section{Results and Discussions}

\subsection{Data Validation and Recovery}

Data collected by AEPC from April, 2001, to December, 2005, has been analyzed. All raw data was subjected to a series of tests and filters to remove faulty or corrupt data points. The gross percentages of data recovered (ratio of the number of raw data points received to data points expected) and net availability (ratio of the number of data points after filtration to raw data points) are shown in Table 1. It is evident that data availability for Kagbeni at $20 \mathrm{~m}$ in 2005 and Thini in 2001 is relatively low. Hence, these data sets not considered in further analysis. 
Table 1: Gross and Net Availability of Wind Data

\begin{tabular}{|l|c|c|c|c|c|c|c|c|}
\hline \multirow{3}{*}{ Year } & \multicolumn{4}{|c|}{ Kagbeni wind mast } & \multicolumn{5}{c|}{ Thini wind mast } \\
\cline { 2 - 10 } & \multicolumn{2}{|c|}{ Gross Recovery (\%) } & \multicolumn{2}{c|}{$\begin{array}{c}\text { Net Availability } \\
(\%)\end{array}$} & \multicolumn{2}{|c|}{ Gross Recovery (\%) } & \multicolumn{2}{c|}{ Net Availability (\%) } \\
\cline { 2 - 9 } & $10 \mathrm{~m}$ & $20 \mathrm{~m}$ & $10 \mathrm{~m}$ & $20 \mathrm{~m}$ & $10 \mathrm{~m}$ & $20 \mathrm{~m}$ & $10 \mathrm{~m}$ & $20 \mathrm{~m}$ \\
\hline $\begin{array}{l}200 \\
1\end{array}$ & 70.96 & 70.96 & 70.74 & 70.43 & 21.88 & 21.88 & 21.75 & 21.63 \\
\hline $\begin{array}{l}200 \\
2\end{array}$ & 80.92 & 80.92 & 80.25 & 80.38 & 84.75 & 81.39 & 84.32 & 77.27 \\
\hline $\begin{array}{l}200 \\
3\end{array}$ & 97.68 & 97.68 & 97.18 & 96.78 & 94.55 & 94.55 & 93.78 & 93.26 \\
\hline $\begin{array}{l}200 \\
4\end{array}$ & 98.21 & 98.21 & 97.74 & 96.85 & 98.42 & 98.42 & 97.33 & 97.28 \\
\hline $\begin{array}{l}200 \\
5\end{array}$ & 99.20 & 24.66 & 99.10 & 24.42 & 100.00 & 100.00 & 98.65 & 98.38 \\
\hline
\end{tabular}

\subsection{Wind speed analysis of Kagbeni wind mast station}

Figures 2-5 show the annual, monthly and diurnal wind speed variation at $10 \mathrm{~m}$ and $20 \mathrm{~m}$ heights at the Kagbeni station. All plots show similar patterns of wind flow regardless of year. For example, June is the mostly windy month and wind starts blowing strongly at 9 am, reaching a peak at about $2 \mathrm{pm}$. The diurnal graph (time of day variation) has the most importance in detailed analysis.

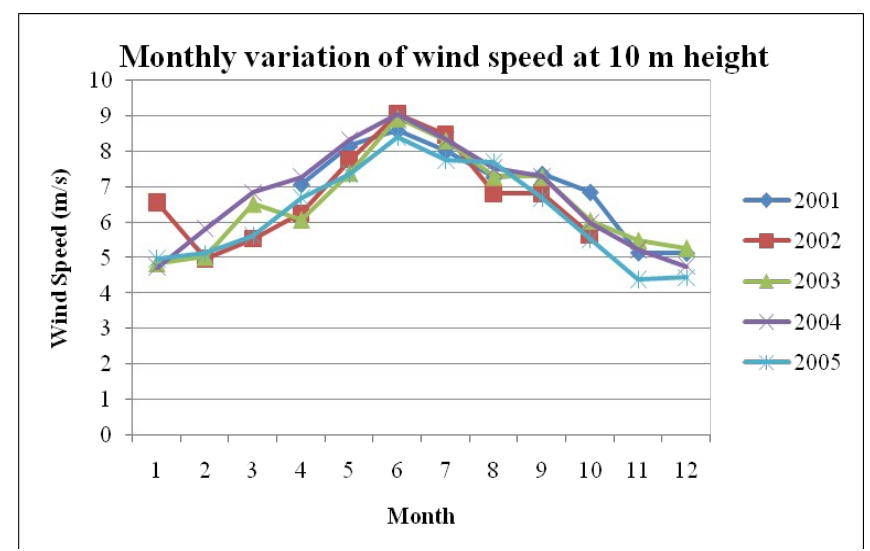

Figure 2: Monthly Variation at $10 \mathrm{~m}$ Height 


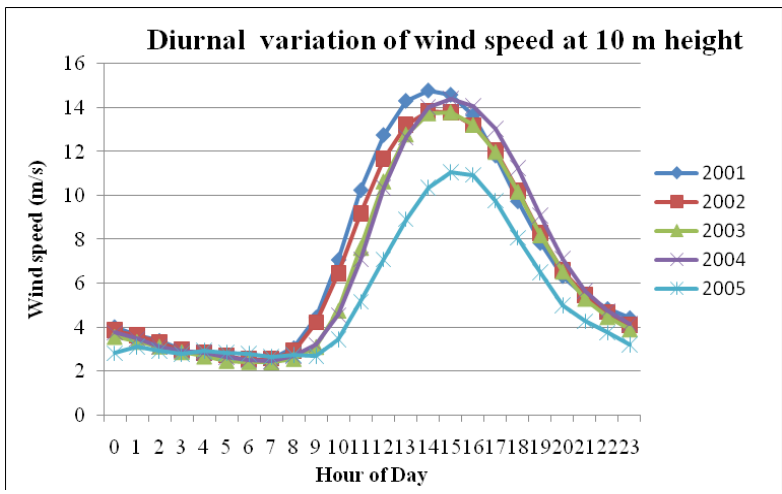

Figure 3 : Diurnal Variation at $10 \mathrm{~m}$ Height 


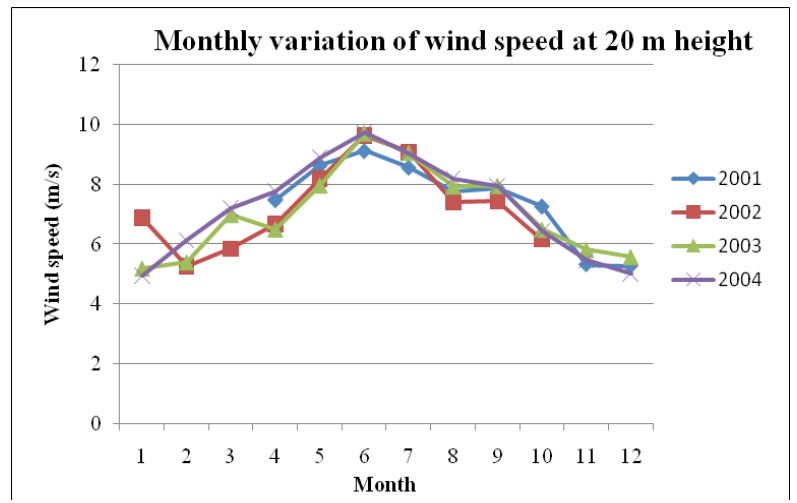

Figure 4: Monthly Variation at $20 \mathrm{~m}$ Height

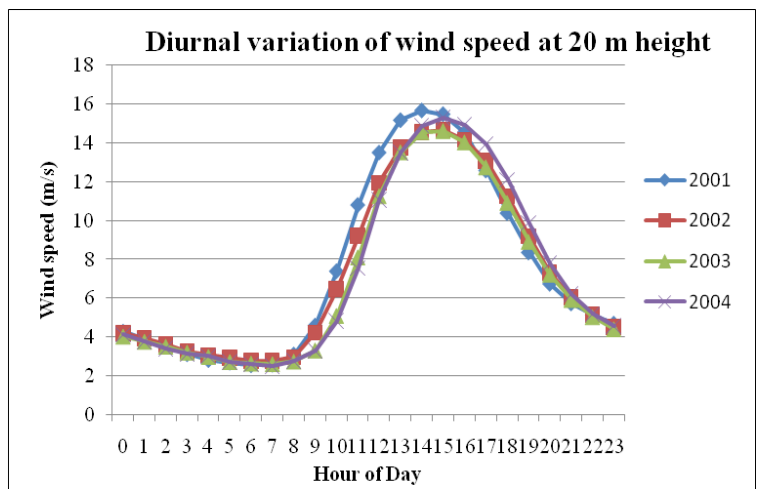

Figure 5: Diurnal Variation at 20 m Height

\subsection{Wind speed analysis of Thini wind mast station}

Figures 6-9 show the same data at the Thini station. In comparison to Kagbeni, Thini has been found to be less windy. The wind speed at $10 \mathrm{~m}$ height in 2001 was found to be unrealistic in comparison to others years, but the cause behind it is unknown.

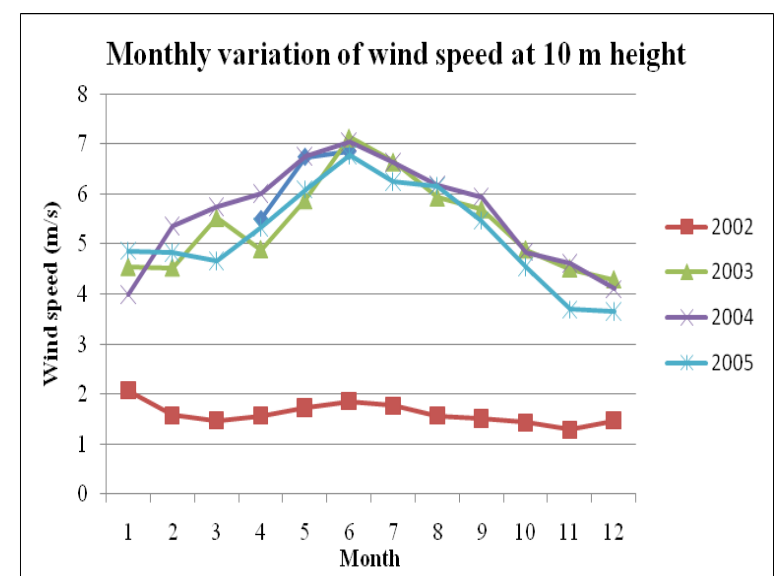

Figure 6: Monthly Variation at $10 \mathrm{~m}$ Height 


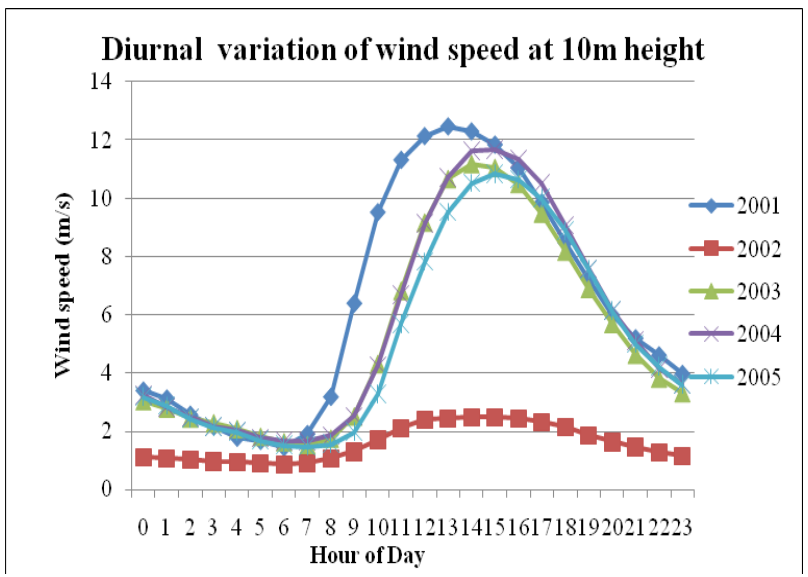

Figure 7: Diurnal Variation at $10 \mathrm{~m}$ Height

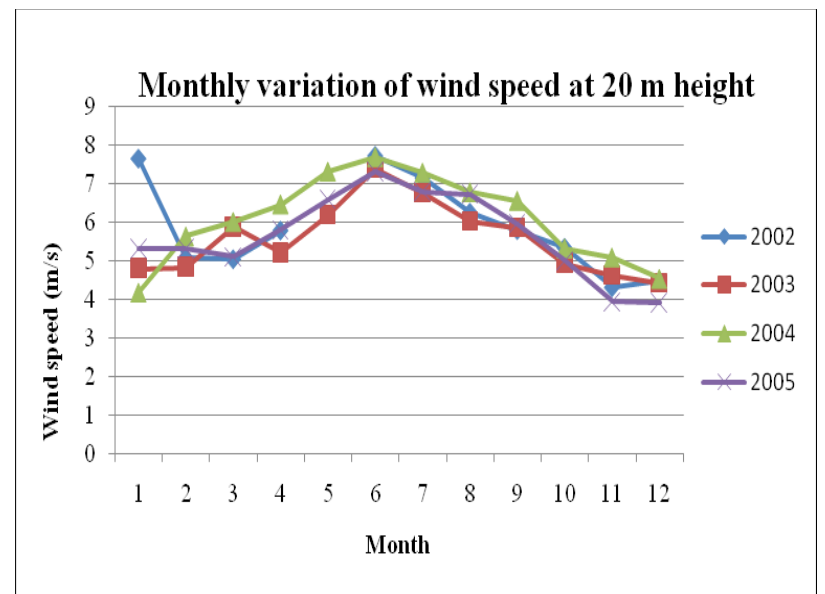

Figure 8: Monthly Variation at $20 \mathrm{~m}$ Height

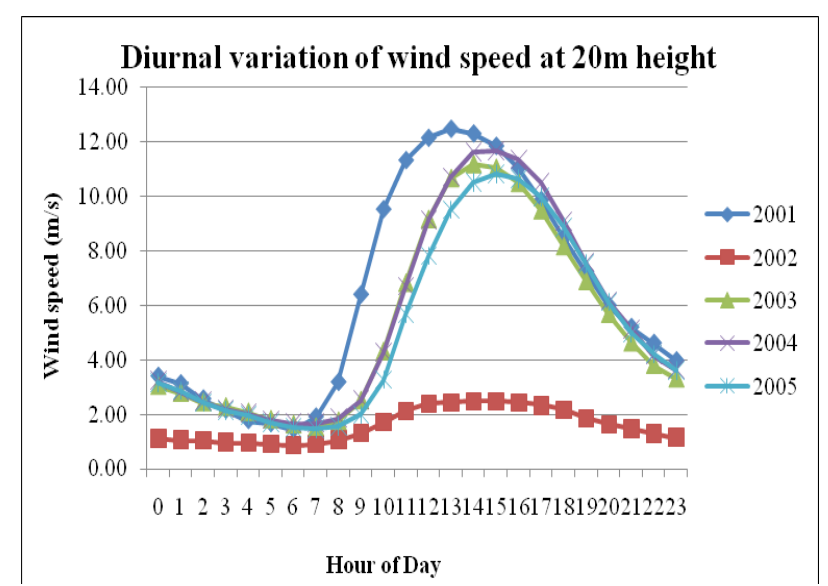

Figure 9: Diurnal Variation at $20 \mathrm{~m}$ Height 


\subsection{Result from WRPLOT}

The average wind speed on an hourly basis has been obtained from the arithmetic mean of the all hourly wind speed data. However, the direction is a vector quantity and thus direct arithmetic mean does not represent the true wind direction for the year.

A reference year wind speed and direction has been analyzed with WRPLOT software to obtain a wind rose. A wind rose is a graphic tool used by meteorologists to give a succinct view of how wind speed and direction are typically distributed at a particular location. The directions of the rose with the longest spoke show the wind direction with the greatest frequency. This is a plot, by compass direction, showing the percentage of time that the wind comes from a given direction and the average wind speed in that direction.
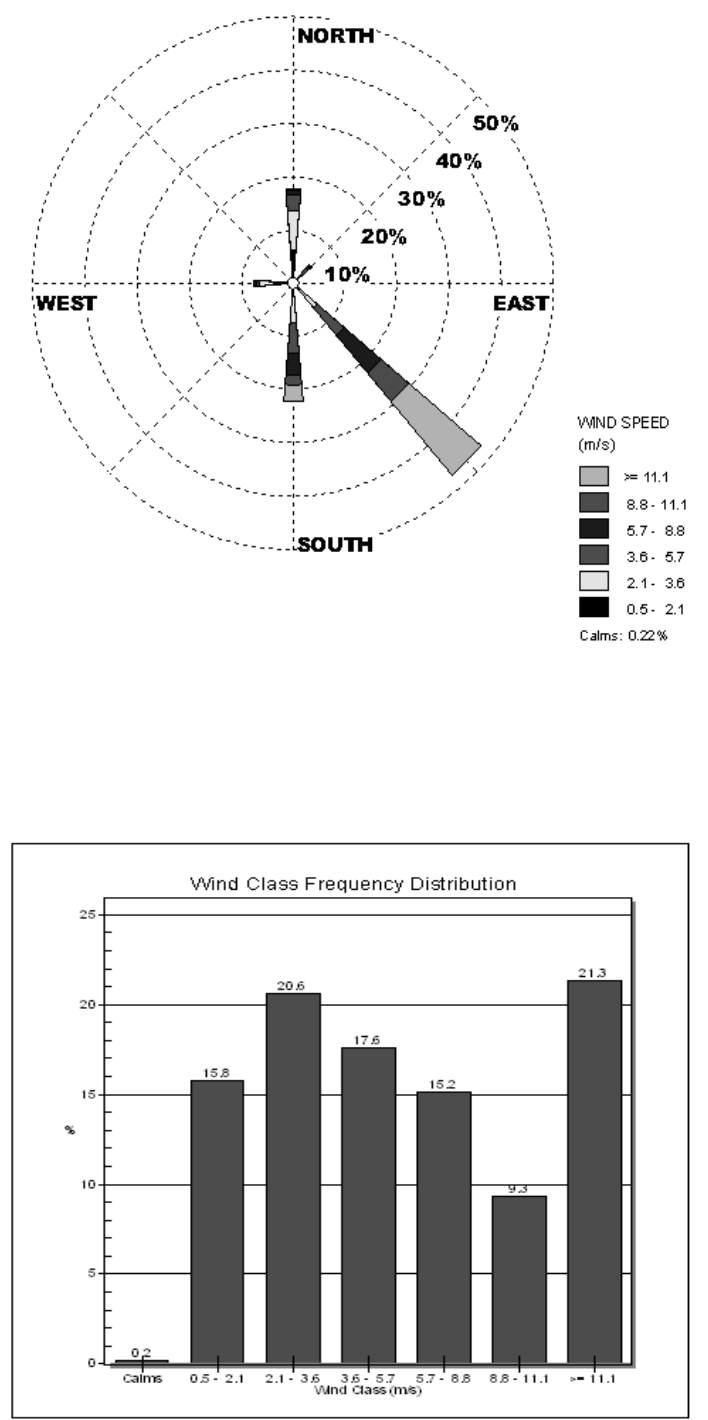

Figure 10: Wind Rose and Frequency Diagram for Reference Year at Kagbeni 
Figure 10 shows the wind rose diagram for the Kagbeni station. The prevailing direction in Kagbeni is from the southeast. Wind blew from the southeast about $45 \%$ of the time and rest of the wind blows from the north and south. This shows that the major consideration should be given to the southeast direction wind, when setting up turbines on the site.
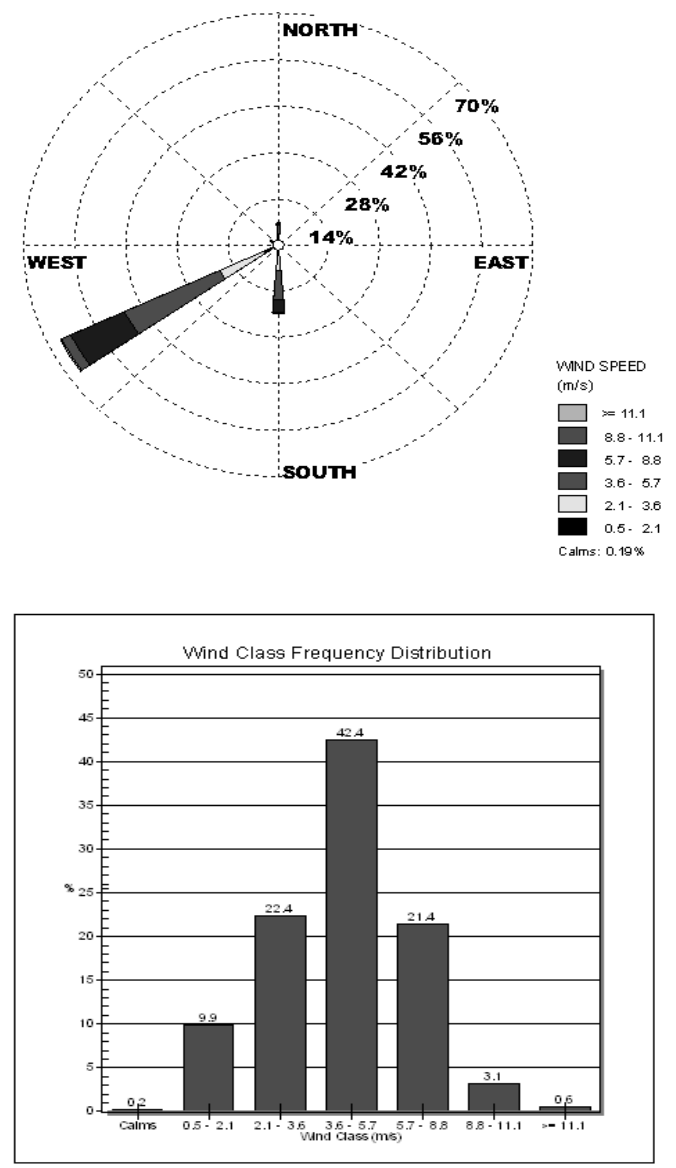

Figure 11: Wind Rose and Frequency Diagram for Reference Year at Thini

At Thini, Figure 11 illustrates that the major portion of the wind blows from the south west direction and small portion blows from the north and south.

\subsection{Wind Resource Grid and Wind Map}

With the help of WAsP, a wind resource grid map of the site has been prepared which shows the values of Weibull parameters (i.e. wind speed, wind power density, shape and scale factor) at all grid points.

The wind resource grid has a resolution of $150 \mathrm{~m}$ and a total of 4745 grid points. This contains a suitable area for a wind farm as the results obtained from GIS and site suitability analysis indicates. Mean wind speed and wind power density have been used to make a wind map for the site. The result shows that the wind speed varies from $2.72 \mathrm{~m} / \mathrm{s}$ to $44.51 \mathrm{~m} / \mathrm{s}$. However, WAsP is known to predict higher wind speeds in complex terrain. The hills and mountains with steep slopes have higher elevations, hence WAsP shows higher wind speeds there, but it may not be 
accurate in this case because the wind flow pattern of the riverbank is mainly due to channelized flow. Figure 12 shows the wind power density map created by WAsp. The value varies from 0.23 $\mathrm{kW} / \mathrm{m}^{2}$ to $173.27 \mathrm{~kW} / \mathrm{m}^{2}$. As expected, topography with higher elevation has higher wind speed and power density.

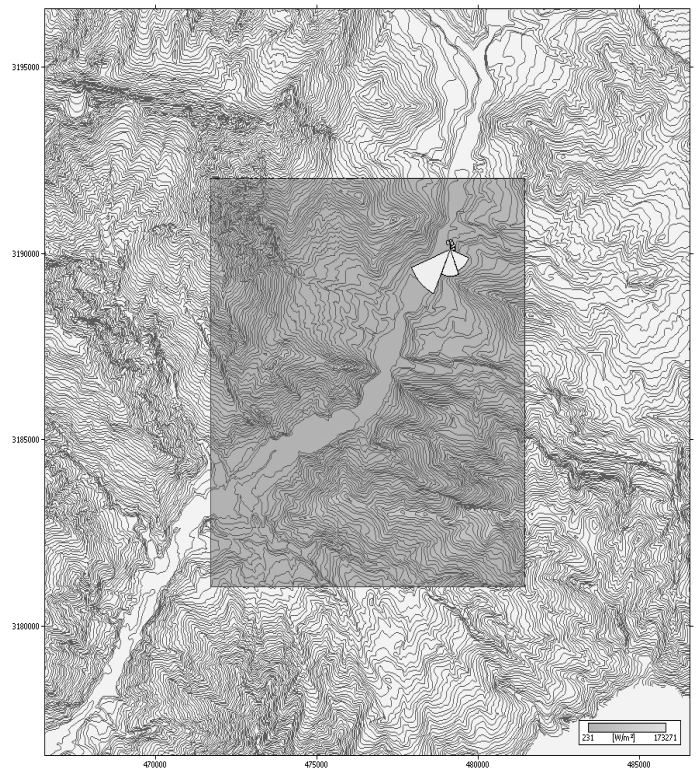

Figure 12: Wind Speed and Power Density Map

\subsection{OpenWind Results}

For this study, openWind software was used in optimizing the proposed wind farm. Overall, 25 wind turbines (model S52-600 kW) [9] are allocated for an installed capacity of $15 \mathrm{MW}$. The wake loss was included using the Eddy Viscosity Model. After 10,000 solution iterations to maximize gross annual energy production, the openWind results were reported [7, 8]. The gross annual energy production from the wind farm is $63.58 \mathrm{GWh}$ with net annual energy production at $41.66 \mathrm{GWh}$ considering array losses of $1.30 \%$ and an average capacity factor of $31.68 \%$. A sketch of the wind farm layout has been prepared, with the two substations marked in black. Substation 1 and 2 collect energy from 12 and 13 turbines, respectively. 


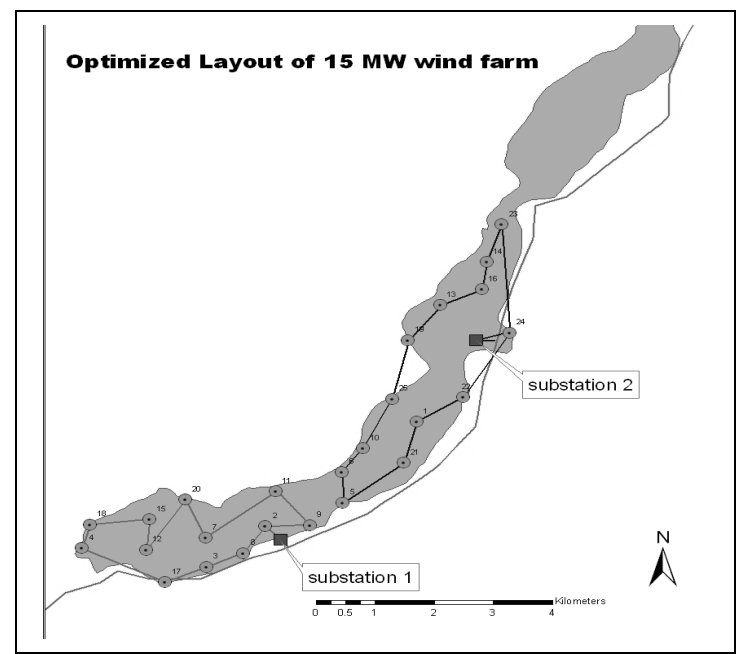

Figure 13: Optimized Wind Farm Layout

\subsection{Financial Analysis}

The net available energy from the wind farm is $41.66 \mathrm{GWh}$. An attempt has been made at financial analysis, considering different loss scenarios at different tariff rates [4]. With the net energy available at $41.66 \mathrm{GWh}$ and varying tariff rates, the NPV and IRR is shown in Figure 14. In this case, at the current electricity tariff rate of NRs 3.8, NPV of the wind farm is negative and hence the project is financially unfeasible for a MARR of $16.1 \%$. Similarly, the NPV and IRR at different tariff rates are computed and when increasing the tariff rate beyond NRs 6 , the project becomes financially feasible.

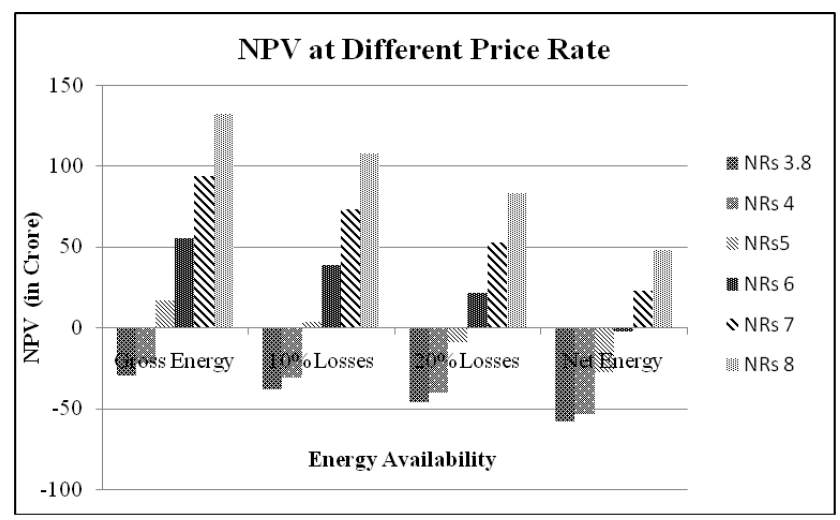

Figure 14: NPV at Different Tariff Rate 


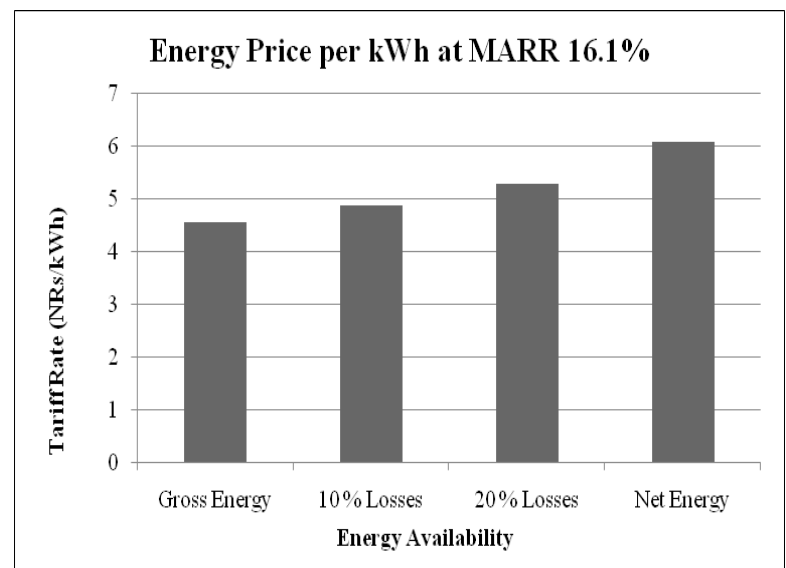

Figure 15: Tariff Rate Setting on MARR

Figure 15 shows the tariff rates that result in a MARR of $16.1 \%$. In a breakeven scenario with a project life of 25 years, if the net energy availability is used, price per kWh of electricity is NRs 6.10 and if gross energy can be captured then the tariff rate is NRs 4.57

\section{Conclusion}

From the study, the following conclusions are drawn:

1. Gross and net availability of wind data at both the mast stations, except in 2001 at Kagbeni and 2005 at Thini, is very significant. There is no significant inter annual variation in wind speed except in 2002 at Thini. Analysis shows that the Kagbeni station is windier than Thini and diurnal variation in wind speed at both stations follows a similar pattern. Wind speed begins increasing around 8:00 am to 9:00 am and reaches to peak about 12:00 pm to 2:00 pm.

2. Average annual wind speed and power density at the Kagbeni wind mast are $7.95 \mathrm{~m} / \mathrm{s}$ and $852 \mathrm{~W} / \mathrm{m}^{2}$, respectively. Wind maps produced for the study site shows the variation of wind speed and wind power density varies from $2.72 \mathrm{~m} / \mathrm{s}$ to $44.51 \mathrm{~m} / \mathrm{s}$ and $0.23 \mathrm{~kW} / \mathrm{m}^{2}$ to $173.27 \mathrm{~kW} / \mathrm{m}^{2}$, respectively.

3. An optimized layout of a $15 \mathrm{MW}$ wind farm comprised of twenty five S52-600 kW turbines, was developed by openWind software. The result yields an annual gross energy of 63.58 $\mathrm{GWh}$, and a net energy of $41.66 \mathrm{GWh}$ with gross capacity factor $31.68 \%$.

4. Preliminary financial analysis shows that to meet a project MARR of $16.1 \%$, an average cost per kWh of electricity generated would be NRs 4.57 to 6.10 under different energy availability scenarios. However, in this preliminary analysis, equipment transportation costs have not been considered in detail.

5. The site is technically feasible from a wind energy availability standpoint. However, it is not possibile to develop such large scale wind farm at this location because of site accessibility issues. Basic infrastructure and other developments are in progress and hence this site ,may be a viable for wind farming in future.

\section{Recommendations}

The following are recommendations for future work: 
1. This study is based on data with a 1 hour resolution but the industry demands higher resolution data, preferably 10 minutes, for resource assessment and detailed feasibility studies. Analysis with such high resolution data is recommended before developing this site for utility scale generation.

2. The WAsP software used in this study is known to predict incorrectly high values in complex terrain and as expected it shows the terrain with high elevations has higher wind resource. Wind mapping software such as MeteoDyn or WindSim, which are based on computational fluid dynamics, are recommended for such a complex terrain.

3. The cost considerations in this study are taken mainly from various existing literature and hence they are based on average cost per $\mathrm{kW}$ as capital cost and per $\mathrm{kWh}$ as generation cost. Therefore, the results achieved in financial analysis may not reflect the exact cost incurred in establishing the actual wind farm on that site. Reliable cost estimations with actual transportation costs should be considered for a detail financial feasibility analysis.

4. The wind map for the selected area has been derived from a single mast station and hence mapping the area considering two masts may enhance better result.

5. The losses considered in openWind software are tentative and thus a detailed analysis with site specific information is recommended to compute net and gross energy capture.

6. The conclusions made are based on a preliminary study and the analyses made are site specific, limited by the study boundary and subject to assumptions. A comprehensive feasibility study of a more sensitive nature will improve the results reached, and thus it is recommended.

\section{Acknowledgements}

We would like to express our sincere gratitude to the Alternative Energy Promotion Center (AEPC) for financial support in traveling to the project area. We are very thankful to Dr. Tri Ratna Bajracharya, the director of the Center for Energy Studies (CES); the Department of Mechanical Engineering and the National Alternative Energy and Engineering Service (NAEES) for their support.

\section{REFERENCES}

SWERA, 2008, "Solar and Wind Energy Resource Assessment in Nepal-GIS Part", UNEP/GEF,

ESMAP, 2007, Technical and Economic Assessment of Grid, Mini-Grid and Off-Grid Electrification Technologies, The World Bank Group, paper no. 121/07, pp 91-98, Annex-D1 
[8] http://www.awstruewind.com

[9] http://www.suzlon.com/products/S 52-600 kW 